\title{
Islet cell antibodies and other markers of autoimmunity and diabetes mellitus in Nauruans
}

\author{
S.Bakos ${ }^{1}$, I.R.Mackay ${ }^{1}$, M.J. Rowley ${ }^{1}$, W. Knowles ${ }^{2}$ and P.Zimmet $^{1,3}$ \\ ${ }^{1}$ The Centre for Molecular Biology and Medicine, Monash University, Clayton, Australia ${ }^{2}$ Molecular Diagnostics, Inc., West Haven, \\ Connecticut, USA, and ${ }^{3}$ International Diabetes Institute, Caulfield General Medical Centre, Caulfield South, Australia
}

\begin{abstract}
Summary. Among the population of Nauru there is a high prevalence of diabetes with onset in early adult life. To ascertain whether autoimmunity to islet cell antigens contributes to this diabetes, a population survey of serum autoantibodies was performed. Subjects were grouped into euglycaemic control subjects, those with impaired glucose tolerance, and those with diabetes subdivided according to duration of disease. No subject was positive by immunofluorescence for islet cell autoantibodies. Various other autoantibodies to nu-
\end{abstract}

clear, thyroid and gastric autoantigens were detectable, at comparable frequencies in the three groups. This population study on Nauruan subjects selected to include those in the early phases of disease negates a contribution from islet cell autoimmunity, and thus supports the concept that the disease is the Type 2 (non-insulin-dependent) type.

Key words: Diabetes, autoimmunity, autoantibodies, islet cell antibodies, Nauru.
Pertinent to the whole area of epidemiological and clinical research on diabetes mellitus and quite apart from considerations on management, is the question of the appropriate classification of this heterogenous disorder [1]. Over 50 years ago, Himsworth proposed that there were at least two clinical types of diabetes, one of which was caused by true insulin deficiency [2]. It was not until the development of a bioassay for insulin in 1949 [3] that scientific credibility became attached to his suggestion. Further confirmation, a decade later, came with the development of the insulin radioimmunoassay [4]. The absence or presence of circulating immunoreactive insulin in young vs older diabetic patients validated the earlier widespread use of the terms "juvenile-onset" and "maturity-onset" diabetes for the two major forms of diabetes.

In 1980, the World Health Organization Expert Committee on Diabetes Mellitus recommended the alternative terms insulin-dependent diabetes mellitus (IDDM) and non-insulin dependent diabetes mellitus (NIDDM) [5]. The terms Type 1 (insulin-dependent) and Type 2 (noninsulin-dependent) diabetes are also used to describe these two types. Type 1 diabetes has been used in a pathogenic sense to describe the particular form of diabetes associated with certain genetic markers and with characteristics of an autoimmune disease [6].

Type 2 diabetes accounts for approximately $80-90 \%$ of the total burden of diabetes in developed countries and al- most $100 \%$ in many developing countries $[7,8]$ whereas Type 1 occurs predominantly among Caucasoid populations [9]. Type 1 is now accepted as an autoimmune disease and markers of the autoimmune process, including islet cell antibodies (ICA) and other organ-specific antibodies, may be present for years before a clinical diagnosis [10-12]. In contrast, autoimmune markers in Type 2 diabetes, in Caucasoids [10] or in other populations [13, 14] are either absent or present at very low frequency. Of particular interest are populations with a high prevalence of Type 2 diabetes, notably the Pima Indians [15] and Nauruans [16], among which the onset of disease can occur at an unusually young age, 20-30 years, so making the differentiation of the two types difficult and invalidating the older "juvenile" and "maturity" onset classification. Moreover, although Type 2 diabetes is held to be associated with insulin resistance, this may be a component of secretory failure of islet Beta cells [17].

Accordingly, we designed a study of ICA and other autoimmune markers among the population of Nauru which has a very high prevalence of diabetes, based on normal subjects, persons with impaired glucose tolerance (IGT) presumed to present a pre-diabetic group at higher risk of developing diabetes [1, 18], and established diabetic subjects. The inclusion of prediabetic subjects was to maximise the possibility of detecting ICA, if they were present at any stage of diabetes among Nauruan subjects. 


\section{Subjects and methods}

\section{The Nauruan population}

Nauru is an isolated island in the Central Pacific and its inhabitants are Micronesians. Modernization of the population through the affiuence acquired by the mining of phosphate has led to serious public health problems $[16,19]$. The way of life has changed from traditional to modern. Large quantities of imported food and drink are consumed and Nauruans exhibit a high prevalence of glucose intolerance, alcohol consumption, cigarette smoking and obesity [19]. There has been a dramatic increase in the frequency of chronic noncommunicable diseases such as diabetes [19] and Nauruans have a prevalence and incidence of diabetes [20], believed to be Type 2 or the non-insulin-dependent type, second only to that found in the Pima Indians of Arizona, USA [21]. The age-standardized prevalence of diabetes is ten times that of the $3.4 \%$ seen in Australian Caucasians [21]. It appears that Nauruans have an increased genetic susceptibility to diabetes and that the environmental change unmasks the disease [7].

In February 1987 the entire Nauruan population was screened for hepatitis $B$ infection. On this occasion all individuals aged 15 years and over were also screened for diabetes [23,24]. This prevalence study reaffirmed the extremely high prevalence of diabetes that had first been noted in this population in 1975 [16]

\section{Survey procedure}

Full details of sample selection and survey methodology have been published elsewhere $[23,24]$. In brief, in 1987, all eligible subjects were asked to fast overnight and attend a central survey site the following day. Of the 1497 subjects who were eligible, the response rate was $86 \%$, i. e. 1287 subjects. Those who did not have a validated history of diabetes underwent a screening procedure for diabetes, as described [24]. The diagnostic criteria were based on recommenda tions by the World Health Organization (WHO) in 1985 for classification of glucose tolerance status. Diabetes mellitus was diagnosed if the 2 -h plasma glucose concentration was $11.1 \mathrm{mmol} / \mathrm{l}$ or greater, and IGT was diagnosed if the 2 -h plasma glucose concentra tion was $7.8 \mathrm{mmol} / 1-11.0 \mathrm{mmol} / \mathrm{l}$. The survey included ascertain ment of body mass index (BMI) and weight. Consent to participate was given by the subjects and the study was given approval by the Ethics Committee, Alfred Hospital, Melbourne.

\section{Subjects}

Of these previously collected blood samples from the survey cohort (all fasting samples, except one 2-h specimen), 245 were tested for the presence of autoantibodies. Three groups of subjects were identified. There were 91 subjects with diabetes of whom 30 were taking oral hypoglycaemic therapy and only one was being treated with insulin, 72 with IGT, and 82 with normal glucose tolerance values. Of the 91 diabetic subjects, 20 were "newly diagnosed" meaning that the presence of diabetes was ascertained at the actual time of the survey; the remainder could be segregated into those with diabetes of less than 10 years duration or greater than 10 years duration. The three groups were comparable for age and sex, allowing for a 5-year margin for an age comparison. Of the 245 people studied, $147(60 \%)$ were females and 98 were $(40 \%)$ males. Data (males:females) for mean BMI (SE in parentheses) were for normal subjects, $31.5(1.1)$ : 36.3 (1.1); for the IGT group, 34.6 (1.3): 37.7 (1.4); and for the diabetic group, 33.0 (1.3): 35.7 (1.2). Corresponding data for mean body weight $(\mathrm{kg})$ for the three groups were for normal subjects, 87.6 (3.3): 86.8 (3.2); for the IGT group, 96.2 (3.6): 90.0 (3.5); and for the diabetic group $91.0(3.5): 85.9$ (3.1).

\section{Autoantibodies}

ICA was tested for by indirect immunofluorescence using human pancreas as a substrate. The pancreatic tissue from an 18-year-old organ donor of blood group 0 was cut into $5 \mathrm{~mm}$ cubes and immediately frozen in liquid nitrogen. Cryostat sections $(5 \mu \mathrm{m})$ were placed on gelatinised glass slides, air-dried for $2 \mathrm{~h}$ and stored at $-70 \mathrm{C}$. Serum diluted $1: 2$ and $1: 4$ in $4 \%$ bovine serum albumin (BSA) in phosphate buffered saline $\mathrm{pH} 7.4$ (PBS) was applied to each section, the slides were washed in PBS and incubated for $30 \mathrm{~min}$ with fluorescein isothiocyanate-labelled rabbit antibody to human immunoglobulin G (FITC-IgG) (Silenus, Hawthorn, Victoria, Australia) which was diluted 1:30 in 1\% BSA-PBS. After washing and mounting, the slides were read by two independent observers. Each assay included a negative control serum diluted $1: 2$ and $1: 4$ and a positive serum reactive to a titre of $1: 64$, and established to contain 160 Juvenile Diabetes Foundation (JDF) units of activity per $\mathrm{ml}$; this represents $\sim 3$ JDF units at the 1:64 dilution. The positive control serum was tested at $1: 8$ and $1: 16$

\section{Other antibodies}

Sera were tested by indirect immunofluorescence for antibodies to nuclei using HEp-2 cells (Immuno concepts, Inc., Sacramento, Calif., USA), and to smooth muscle and gastric parietal cells and mitochondria using cryostat sections $(5 \mu \mathrm{m})$, from a composite block containing mouse stomach, kidney and liver. The substrate, HEp-2 cells or frozen section, were incubated with serum at a dilution of 1:40 for $30 \mathrm{~min}$, washed with PBS and then exposed to FITC-IgG at a dilution of 1:120. The slide was rewashed, mounted and examined. Tests were scored as positive or negative at the one serum dilution of 1:40; titrations were not performed. Tests for thyroglobulin antibodies and thyroid microsomal antibodies were performed by haemagglutination using diagnostic kits (Thymune-M and Thymune $\mathrm{T}$, Wellcome Diagnostics, London, UK).

\section{Immunoblotting on bovine heart mitochondria}

Because certain sera gave a weak cytoplasmic staining on liver sections by immunofluorescence, samples were examined by immunoblotting on bovine heart mitochondria. Bovine heart mitochondria were prepared by differential centrifugation by standard procedures from homogenised bovine heart [25]. Polyacrylamide gel electrophoresis was performed and the mitochondrial extract was separated under reducing conditions on $12.5 \%$ gels. After transfer of proteins to nitrocellulose membrane and blocking of uncovered sites with $5 \%$ (weight to volume) skimmed milk powder, the nitrocellulose was cut into strips and these were incubated overnight with human sera at dilutions 1:500 and/or 1:1000. Horseradish peroxidase coupled anti-human IgG (Silenus) diluted 1:500 was used as second antibody and 4-chloro naphthol as substrate.

\section{Statistical analysis}

Chi square tests with continuity corrections were performed across the diabetes status groups to test for significance of differences in frequency of autoantibodies.

\section{Results}

The overall results for autoantibodies are shown in Table 1 . No serum from any of the groups, control subjects, IGT or diabetes was positive for ICA as judged by 
Table 1. Prevalence in males and females, and frequency of autoantibodies $(\mathrm{a} a b)$ in normal subjects, those with impaired glucose tolerance (IGT) and diabetic subjects among Nauruan population. The differences were not significant by chi square

\begin{tabular}{llll}
\hline Autoantibody & $\begin{array}{l}\text { Normal } \\
32: 50^{\mathrm{a}} \\
47 \pm 13 \text { years } \\
(25-73)^{\mathrm{b}}\end{array}$ & $\begin{array}{l}\text { IGT } \\
30: 42\end{array}$ & $\begin{array}{l}\text { Diabetes } \\
(25-70)\end{array}$ \\
& 0 & 0 & $\begin{array}{l}36: 55 \\
(25-74)\end{array}$ \\
\hline $\begin{array}{l}\text { Islet cell (ICA) } \\
\begin{array}{l}\text { Thyroid } \\
\text { microsomes (TM) }\end{array}\end{array}$ & $0,5(6)^{\mathrm{c}}$ & 0 & 0 \\
$\begin{array}{l}\text { Thyroglobulin (Tg) } \\
\text { Gastric parietal cell }\end{array}$ & $0,1(1)$ & $0,3(4)$ & $0,4(4)$ \\
(GPC) & $1,3(5)$ & 0 & $0,2(2)$ \\
Nuclear (ANA) & $6,4(12)$ & $7,10(24)$ & $4,7(12)$ \\
Any a ab & $7,13(25)$ & $7,13(28)$ & $8,20(30)$ \\
\hline
\end{tabular}

a Numbers refer to males:females in that group. ${ }^{b}$ Age and standard deviation and range (in parentheses). ${ }^{c}$ Numbers in parentheses are percent frequency of autoantibody d Significantly different (chi square) across the diabetes $(p=0.015)$

Table 2. Prevalence (\%) of various autoantibodies (aab) in diabetic subjects in relation to duration of diabetes compared with subjects with impaired glucose tolerance (IGT). The differences were not significant by chi square

\begin{tabular}{llllll} 
Autoantibody $^{\mathrm{a}}$ & & \multicolumn{3}{l}{ Duration of diabetes $^{\mathrm{b}}$} \\
\cline { 5 - 6 } & & IGT & $\begin{array}{l}\text { Newly } \\
\text { diagnosed }\end{array}$ & \multicolumn{2}{l}{ Duration } \\
\cline { 5 - 6 } & & & & \multicolumn{2}{c}{$<1-10 \mathrm{yrs}>10 \mathrm{yrs}$} \\
& & $n=72$ & $n=20$ & $n=41$ & $n=29$ \\
\hline ICA & $(0)$ & 0 & 0 & 0 & 0 \\
TM & $(6)$ & 0 & $1(5)$ & 0 & $2(7)$ \\
Tg & $(1)$ & $3(4)$ & $1(5)$ & 0 & 0 \\
GPC & $(5)$ & 0 & $2(10)$ & $5(12)$ & $4(14)$ \\
ANA & $(12)$ & $17(24)$ & $1(5)$ & $4(10)$ & $6(21)$ \\
Any a ab & $(25)$ & $20(28)$ & $5(25)$ & $9(22)$ & $12(41)$ \\
\hline
\end{tabular}

a Percent positive for control group in parenthesis: ICA, islet cell; TM, thyroid microsomes; $\mathrm{Tg}$, thyrogloblin; GPC, gastric parietal cell; ANA, nuclear. ${ }^{\mathrm{b}}$ For one positive case in which there were antibodies to TM and Tg, the duration of diabetes was unknown

comparison with serial dilutions of the positive control serum on every assay run. However, autoantibodies to various other antigens were detected in each of the three groups. As in all population surveys, there was a higher frequency of autoantibodies in females than males, for all groups. The frequency of various autoantibodies shows a degree of scatter for the three groups. The overall frequency of antibodies was higher (non-significantly) in the diabetic group, but there were few notable differences in frequency of individual autoantibodies. The immunofluorescence patterns of antinuclear reactions were fine speckled or nucleolar; a homogeneous pattern was not observed. None of the sera was reactive with smooth muscle.

The prevalence of the various autoantibodies in diabetic subjects was not related to the duration of diabetes when diabetic subjects were analysed in subgroups of newly-diagnosed $(n=20)$, duration 1-10 years $(n=41)$ and duration greater than 10 years, as shown in
Table 2. In particular, even among the 20 newly-diagnosed diabetic subjects, none gave a positive test for ICA.

Some sera were observed to give an atypical cytoplasmic staining by immunofluorescence with apparent mitochondrial localization, although not of the M2 pattern characteristic of primary biliary cirrhosis. Reactivity with mitochondrial antigens was further investigated by immunoblotting against a preparation of bovine heart mitochondria. Of the 42 sera tested, 14 normal subjects, 17 with IGT and 11 diabetic subjects, none gave the immunoblotting pattern characteristic of primary biliary cirrhosis with bands of mol. wt. of 74 kilodalton (kd), $52 \mathrm{kd}, 45 \mathrm{kd}$ and $39 \mathrm{kd}$ [26]. However, 19 of the 42 sera reacted strongly with an $18 \mathrm{kd}$ component of the mitochondrial preparation. This band was observed in each of the three groups, and so had no relationship to the occurrence of diabetes. Overall the frequency of this reactivity among Nauruan sera, 18 of 42 subjects ( $43 \%$ ), was substantially higher than the frequency among Australian Caucasians, 7 of 61 subjects $(12 \%)$. The nature of this $18 \mathrm{kd}$ mitochondrial antigen has not been identified.

\section{Discussion}

Diabetes which is apparently of the non-insulin-dependent type (Type 2), occurs in high frequency in Nauru, comparable with that among Pima Indians $[15,16]$. These two populations have the highest prevalence recorded. In view of the possibility that some of the relatively young Nauruan subjects with apparent Type 2 diabetes in fact had Type 1 autoimmune diabetes, we conducted a survey for the occurrence of islet cell and other autoantibodies. The unique features of the study were first, the inclusion of a group of "pre-diabetic subjects", i.e. subjects with IGT, as these are the subjects most likely to progress to frank diabetes [18], and second the division of the diabetic subjects according to the duration of their disease. Individuals with IGT, or those of known recent-onset diabetes, would be most likely to show islet cell autoantibodies if they were to be detected in this population.

Our study showed that islet cell antibodies were lacking in all groups, yet the 245 subjects tested showed a frequency of other autoantibodies similar to that observed in Caucasoid populations of comparable age and sex [27]. Among these autoantibodies were reactivities with thyroid and gastric antigens that are associated in Caucasoids with islet cell antibodies [28].

We therefore conclude that the unusually high frequency of diabetes among Nauruans, including relatively young subjects, is exclusively of the Type 2 (non-insulindependent) type and that autoimmunity to pancreatic islet cells plays no part in its pathogenesis. This conclusion is consistent with the features of diabetes in Nauru, including its clinical associations [19,29], natural history [18] and the normal to high C-peptide concentrations [30]. We predict that our findings could be extrapolated to other indigenous populations subjected to abrupt changes in lifestyle associated with "Westernization".

There is at least one other important perspective relating to this study. Diabetes has become very common in 
newly industrialized nations particularly in Asia and the Pacific [7,31]. Often, the onset of diabetes appears to be that of Type 2 (non-insulin-dependent) yet within a few years, the subject progresses to insulin-dependency raising the question that there is a subgroup of people with "typical Type 2 onset" who in fact represent a late-onset Type 1 category. It may be expected that more detailed examination of this subgroup in various locations may reveal the presence of ICA and certain HLA phenotypes which would allow a better prediction of the natural history of the disease, and its classification. There is already evidence that this is the case in Caucasoid populations [32].

Our results are in keeping with earlier studies for indigenous populations. Knowler et al. [14] examined ICA and 12 other autoantibodies in Pima Indians, with onset of diabetes aged $17-47$ years, with results similar to our own. They concluded that diabetes in the Pima Indians, even those with an onset below 25 years of age, is almost entirely of the Type 2 (non-insulin-dependent) form. Morrison et al. [33] found no evidence of ICA positivity in 42 Jamaican Blacks with diabetes aged from 6 to 77 years; 24 were taking insulin and of these, 8 had an onset of diabetes when under 40 years of age. McLarty et al. [34] investigated the prevalence of ICA together with other organ-specific autoantibodies in 122 black Tanzanians with newly-presenting diabetes. ICA were found in $8.6 \%$ of those regarded as having Type 1 diabetes and $6.8 \%$ of insulin-requiring subjects regarded as Type 2; it is difficult to explain the frequency of ICA positivity in subjects in that study considered to have Type 2 diabetes. In any event, the authors concluded that there was no major association between diabetes and ICA in black Tanzanians.

In conclusion, we assessed whether pancreatic islet cell autoantibodies, as a marker of autoimmune pathogenesis, were present in 91 Nauruan subjects with diabetes presumed to be Type 2 diabetes, grouped into pre-diabetic subjects, recently diagnosed diabetic subjects and subjects with long-standing diabetes. Although it would be reasonable to expect ICA to be present in early phases of glucose intolerance if ICA were associated with highly-prevalent diabetes in the Nauru population, none was found. Thus, we find no evidence for autoimmunity in the pathogenesis of diabetes in this population and hence presume that the disease among Nauruans is the (non-insulin-dependent) Type 2 .

Acknowledgements. Statistical analyses were kindly performed by Ms. L. Knight. The study was supported by grants from the Alfred Group of Hospitals Research Fund and the Leon Mow Research Trust. MJR was supported by a Bicentennial Research Fellowship from the Arthritis Foundation of Australia. We are grateful to Ms. S. Fournel and Ms. A. Ford for preparation of the manuscript.

\section{References}

1. Zimmet P, King H (1987) Classification and diagnosis of diabetes mellitus. In: Alberti KGMM, Krall LP (eds) The diabetes annual/3. Elsevier, Amsterdam pp 1-14

2. Himsworth HP (1936) Diabetes mellitus: its differentiation into insulin-sensitive and insulin-insensitive types. Lancet I: 117-120
3. Bornstein J, Lawrence RD (1951) Plasma insulin in human diabetes mellitus. Br Med J 2: 1541-1542

4. Yalow RS, Berson SA (1960) Immunoassay of endogenous plasma insulin in man. J Clin Invest 39: 1157-1175

5. World Health Organization Expert Committee on Diabetes Mellitus (1980) Second report, Technical Report Series 646, WHO, Geneva, pp 8-12

6. National Diabetes Data Group (1979) Classification and diagnosis of diabetes mellitus and other categories of glucose intolerance. Diabetes 128: 1039-1057

7. Zimmet P (1982) Type 2 (non-insulin-dependent) diabetes - an epidemiological overview. Diabetologia 22:399-411

8. Dowse GK, Zimmet PZ (1989) The prevalence and incidence of non-insulin dependent diabetes mellitus. In: Alberti KGMM, Mazze R (eds) Frontiers in diabetes research: current trends in non-insulin-dependent diabetes mellitus. Elsevier, Amsterdam, pp 37-59

9. LaPorte R, Tajima N, Akerblom HR et al. (1985) Geographic differences in the risk of insulin-dependent diabetes mellitus. The importance of registries. Diab Care 8 [Suppl 1]: 101-107

10. Srikanta S, Ganda OP, Rabizadeh DMJ et al. (1985) First degree relatives of patients with type 1 diabetes mellitus. $\mathrm{N}$ Engl J Med 313: 461-464

11. Maclaren NK (1988) How, when and why to predict IDDM. Diabetes 37: 1591-1594

12. Riley WJ, Maclaren NK, Krischen J et al. (1990) A prospective study of the development of diabetes in relatives of patients with insulin-dependent diabetes. N Engl J Med 323: 1167-1172

13. Kobayashi T, Sugimoto T, Itoh T et al. (1986) The prevalence of islet cell antibodies in Japanese insulin-dependent and non-insulin dependent diabetic patients studied by indirect immunofluorescence and by a new method. Diabetes 35: 335-340

14. Knowler WC, Bennett PH, Bottazzo GF, Doniach D (1979) Islet cell antibodies and diabetes mellitus in Pima Indians. Diabetologia 17: 161-164

15. Bennett PH, Rushforth NB, Miller M, Le Compte PM (1976) Epidemiological studies of diabetes in the Pima Indians. Recent Prog Horm Res 32: 333-376

16. Zimmet P, Taft P, Guinea A, Guthrie W, Thoma K (1977) The high prevalence of diabetes mellitus on a Central Pacific island. Diabetologia 13: 111-115

17. Saad MF, Knowler WC, Pettitt DJ, Nelson RG, Charles MA, Bennett PH (1991) A two-step model for development of non-insulin-dependent diabetes. Am J Med 90: 229-235

18. King H, Zimmet P, Raper LR, Balkau B (1984) The natural history of impaired glucose tolerance in the Micronesian population of Nauru: a six-year follow-up study. Diabetologia 26: 39-43

19. Schooneveldt M, Songer T, Zimmet P, Thoma K (1988) Changing mortality patterns in Nauruans - an example of epidemiological transition. J Epidemiol Comm Health 42: 89-95

20. Balkau B, King H, Zimmet P, Raper LR (1985) Factors associated with the development of diabetes in the Micronesian population of Nauru. Am J Epidemiol 122: 594-605

21. Knowler WC, Bennett PH, Hamman RF, Miller M (1978) Diabetes incidence and prevalence in Pima Indians: a 19-fold greater incidence than in Rochester, Minnesota. Am J Epidemiol 108: $497-504$

22. Glatthaar C, Welborn TA, Stenhouse NS, Garcia-Webb P (1985) Diabetes and impaired glucose tolerance: a prevalence estimate based on the Busselton 1981 survey. Med J Aust 143: 436-440

23. Collins VR, Dowse GK, Finch CF, Zimmet PZ, Linnane AW (1989) Prevalence and risk factors for micro- and macroalbuminuria in diabetic subjects and the total population of Nauru. Diabetes 38: 1602-1610

24. Finch CF, Dowse GK, Collins VR, Zimmet PZ (1990) Quantifying the extent to which random plasma glucose underestimates diabetes prevalence in the Nauruan population. Diab Res Clin Practice 10: 177-182

25. Smith AL (1967) Preparation, properties and conditions for assay of mitochondrial slaughterhouse material, small scale. Meth Enzymol 10: 81-86 
26. Mackay IR, Gershwin ME (1989) Molecular basis of mitochondrial autoreactivity in primary biliary cirrhosis. Immunol Today $10: 315-318$

27. Hooper B, Whittingham S, Mathews JD, Mackay IR, Curnow DH (1972) Autoimmunity in a rural community. Clin Exp Inmunol 12:79-87

28. Groop LC, Bottazzo GF, Doniach D (1986) Islet cell antibodies identify latent type I diabetes in patients aged 35-75 years at diagnosis. Diabetes 35:237-241

29. Zimmet $\mathrm{P}$, King H, Taylor R et al. (1984) The high prevalence of diabetes mellitus, impaired glucose tolerance and diabetic retinopathy in Nauru - the 1982 survey. Diab Res 1: 13-18

30. Garcia-Webb P, Zimmet P, Bonser A, King H, Bottomley S (1984) Factors affecting fasting serum C-peptide levels in Micronesians: comparison with a Caucasoid population. Diabetologia 27: 23-26

31. Zimmet P, Dowse G, Serjeantson S, Finch C, King H (1990) The epidemiology and natural history of NIDDM - lessons from the South Pacific. Diab Metab Rev 6: 91-124

32. Groop L, Miettinen A, Groop P-H et al. (1988) Organ-specific auto-immunity and HLA-DR antigens as markers for $\beta$-cell destruction in patients with type 2 diabetes. Diabetes 37: $99-$ 103

33. Morrison EYS, Rosenbloom AL, Maclaren NK et al. (1986) Absence of islet cell autoantibodies in Jamaican blacks with diabetes mellitus. West Indian Med J 35: 35-37

34. McLarty DG, Atharde I, Bottazzo GF et al. (1990) Islet cell antibodies are not specifically associated with insulin-dependent diabetes in Tanzanian Africans. Diab Res Clin Pract 9:219224

Received: 29 April 1991

and in revised form: 1 August 1991

Dr. I.R. Mackay

Centre for Molecular Biology and Medicine

Monash University

Clayton

Victoria 3168

Australia 